a
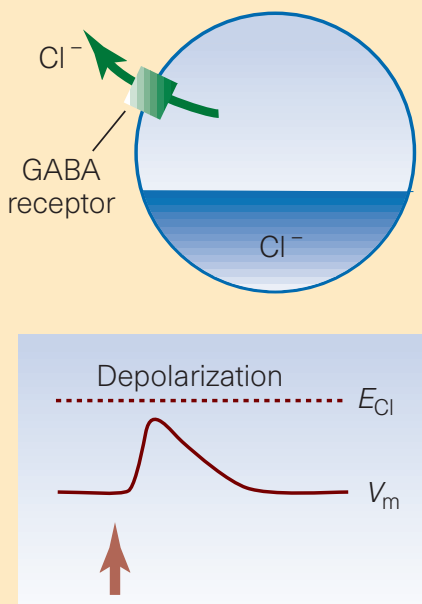

GABA b

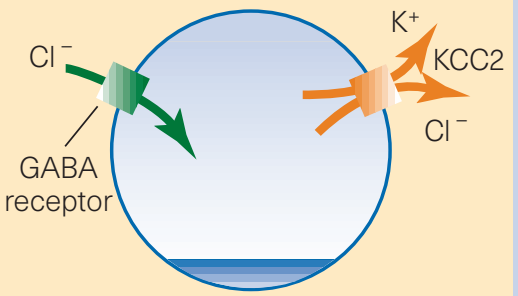

Hyperpolarization

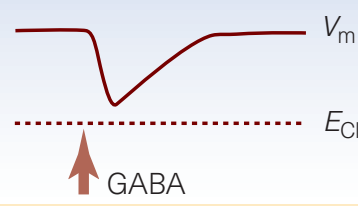

Figure 1 Chloride homeostasis and signalling by the inhibitory neurotransmitter GABA. a, Levels of intracellular $\mathrm{Cl}^{-}$are high, and the equilibrium potential for $\mathrm{Cl}^{-}, E_{\mathrm{Cl}}$, is positive relative to the membrane potential, $V_{\mathrm{m}}$. Opening of $\mathrm{Cl}^{-}$channels by activation of the $\mathrm{GABA}_{\mathrm{A}}$ receptor depolarizes the cell. b, Expression of the KCC2 transporter, studied by Rivera et al. ${ }^{1}$, maintains a low level of $\mathrm{Cl}^{-}$. $E_{\mathrm{Cl}}$ is negative relative to $V_{\mathrm{m}}$ and activation of the $\mathrm{GABA}_{\mathrm{A}}$ receptor inhibits the cell. Immature hippocampal and spinal neurons start life as cells depolarized by GABA (a), and mature into cells in which GABA has a hyperpolarizing action (b). Dorsal root ganglion cells and some nerve terminals are depolarized by GABA into adult life (a).

adult. But, curiously, this excitatory action of GABA can inhibit synaptic signalling between neurons. The GABA acts on receptors located on synaptic terminals where $\mathrm{Cl}^{-}$ is set high. Depolarization ${ }^{5}$ prevents action potentials from being propagated into the nerve terminals, reduces the influx of $\mathrm{Ca}^{2+}$ and, in this way, inhibits transmitter release.

A depolarizing GABA action does not necessarily point to the absence of KCC2. Indeed, depolarization can be induced by quite another mechanism in adult hippocampal cells, where $\mathrm{Cl}^{-}$is set low. The trick is that activation of a GABA receptor opens channels that are permeable to $\mathrm{HCO}_{3}^{-}$as well as $\mathrm{Cl}^{-}$(refs 6, 7). An influx of $\mathrm{Cl}^{-}$tends to hyperpolarize, whereas efflux of $\mathrm{HCO}_{3}^{-}$through the same channel depolarizes the cell. With prolonged stimulation, the $\mathrm{Cl}^{-}$influx increases the concentration of intracellular $\mathrm{Cl}^{-}$, reducing the hyperpolarizing action of $\mathrm{GABA}^{8}$. But because $\mathrm{HCO}_{3}^{-}$is in a dynamic equilibrium with $\mathrm{CO}_{2}$, which can permeate the cell membrane, its depolarizing actions are maintained ${ }^{9}$. In this way, strong activation of GABA receptors can initiate biphasic responses - initially hyperpolarizing and then depolarizing — in adult neurons ${ }^{10}$.

Finally, how could regulation of a transporter molecule such as KCC2 contribute to neuronal plasticity? The KCC2 protein contains several consensus sites for phosphorylation, which are expected to regulate its activity $^{2}$. Might they, by modifying the homeostatic set point for the concentration of intracellular $\mathrm{Cl}^{-}$, underlie the circadian switch in GABA-mediated signalling ${ }^{11}$ in the suprachiasmatic nucleus, from excitatory during the day to inhibitory at night? On a longer timescale, what would happen if KCC2 were downregulated, and how might this be triggered? Traumatic injury, for instance, causes a depolarizing shift in GABA responses with potentially pathological consequences ${ }^{12}$ : the resulting influx of $\mathrm{Ca}^{2+}$ could kill cells, and remodelling of cortical circuits owing to the loss of inhibitory control could contribute to post-traumatic epilepsy. Certainly, homeostasis is not quite so static as it used to be.

Richard Miles is in the Laboratoire de Neurobiologie Cellulaire, INSERM U261, Institut Pasteur, 25 rue

du Dr Roux, Paris cedex 15, France.

e-mail: rmiles@pasteur.fr

1. Rivera, C. et al. Nature 397, 251-255 (1999).

2. Payne, J. A., Stevenson, T. J. \& Donaldson, L. F. J. Biol. Chem. 271, 16245-16252 (1996).

3. Ben-Ari, Y., Cherubini, E., Coradetti, R. \& Gaiarsa, J. L. J. Physiol. 416, 303-325 (1989).

4. Rohrburgh, J. \& Spitzer, N. C. J. Neurosci. 16, 82-91 (1996).

5. Zhang, S. J. \& Jackson, M. B. Science 259, 531-534 (1993).

6. Kaila, K., Voipio, J., Paalasmaa, P., Pasternack, M. \& Deisz, R. A. J. Physiol. 464, 273-289 (1993).

7. Perkins, K. L. \& Wong, R. K. S. J. Neurophysiol. 76, 3886-3894 (1996).

8. Thomson, S. M. \& Gahwiler, B. H. J. Neurophysiol. 61, 501-511 (1989).

9. Staley, K. J., Soldo, B. L. \& Proctor, W. R. Science 269, 977-981 (1995).

10. Alger, B. E. \& Nicoll, R. A. Nature 281, 315-317 (1979).

11. Wagner, S., Castel, M., Gainer, H. \& Yarom, Y. Nature 387, 598-603 (1997)

12. van den Pol, A. N., Obrietan, K. \& Chen, G. J. Neurosci. 16, 4283-4292 (1996).

\section{Cogito in vitro}

The gloomy old orthodoxy about human brain cells was that, in the adult at least, they never divide or re-grow. Brain injury or deterioration was therefore irreversible. This belief now seems pessimistic. The human hippocampus, at least, can regenerate neurons; and mouse brain cells, encouraged by epidermal growth factor, have been successfully cultured in vitro. Last week Daedalus was exploiting these facts with his 'brain pan' — a single layer of brain cells cultured in a petri dish. The idea was for the cells to put out dendrites and axons, which would connect at random with each other. Electrodes lowered onto the cells could fire them, and eavesdrop on the resulting neural communication.

Daedalus now reckons that he has invented the ultimate neural-net computer. The 'strong' theory of neural-net and brain action, he says, is either brilliant or absurd, or possibly both. It asserts that a planless array of randomly wired neurons can learn anything. Neural connections which are reinforced become more easily triggered and more active; those which are neglected become less active. So an utterly planless network like his brain pan could be 'taught' to act as a computer. Even its wiring might grow to meet demand. Routes carrying heavy traffic could well grow more dendrites to carry it.

Daedalus is setting up a brain pan to test these claims. He is fitting it with a dense array of peripheral electrodes to simulate input (sensory) nerves, and another dense array of output (motor) connections. He will feed typical neuralnet tasks into the input array, and assess the response on the output one. Correct responses will be reinforced by repetition; incorrect ones will be extinguished by neglect or counterexample. The first experiments will use mouse brain cells. Human ones might (or might not) be cleverer, but would raise ethical concerns.

The brain pan's education will start with simple signals for elementary evaluation, and will progress towards ever greater subtlety. Ultimately it will be given microphone and TV-camera inputs and hydraulic-actuator outputs, and encouraged to learn its way round the real world - like a mouse or human being. Success will raise deep philosophical problems about minds, meanings and consciousness. Failure will reinforce Daedalus's nagging suspicion that we know nothing whatever about how the brain works.

David Jones 